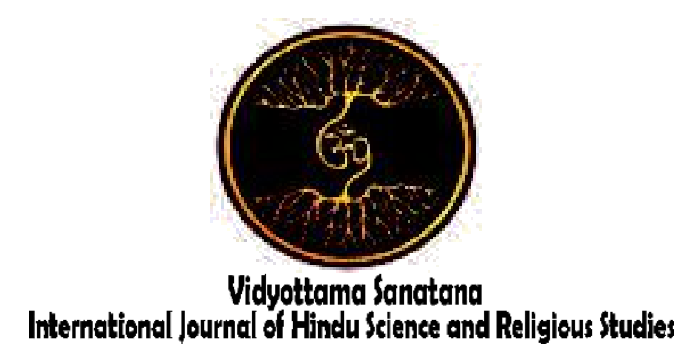

Vol. 3 No. 2 October 2019

\title{
GUESS THE PICTURE ANIMATION APP IN AN EFFORT TO INCREASE THE EFFECTIVENESS OF DISCUSSION STUDENTS
}

\author{
By:
}

I Wayan Damai Yasa, I Made Arsa Wiguna, Heny Perbowosari

Institut Hindu Dharma Negeri Denpasar

E-mail : henyperbowosari@ihdn.ac.id

\begin{abstract}
In line with the development of science, the technology also be a results that was born by the science. Then with technology also any kinds of knowledge can facilitate human in the absorb, received, obtained and develop science. So, between science and technology is two elements in the world of education that can help advances in his transformation knowledge to human. From the technology that simple, its slowly but surely until on sophisticated technology that so quickly can help the performance of human to produce the latest knowledge that have been able to created by human from the results of scientific development that he had. Therefore, technology is very also plays an important role in advancing the world of education. Including lately how humans have been able to find and create a variety of application technology in the form of "Games" or some games that collaborated with educational activities and learning so as to foster a sense of human interest ranging among children until adults to learn a variety of things, while entertain himself.
\end{abstract}

Keywords: Animation App, Discussion Students

\section{INTRODUCTION}

Learning sometimes is something that becomes a dilemma in human beings, especially to the learners in participating learning activities that are regular. This happens because not all people like and are interested to learn in a classroom, but there is also a pattern of human thinking thats want to enjoy the process of learning only by his own volition. But the basic principle, every person would want a learning process that is active, creative, and fun. In addition to 
fulfilling the process of creative learning and fun is how the efforts of the teachers to be able to deliver teaching materials, to give sense and understanding to the learners in order that the learners are more quickly understood and understand the material taught by the teacher. to meet the needs or desire of human to be able to enjoy the education and learning which is creative and fun, the teachers and the education continue to make efforts to develop technology education in order to meet the wishes of the learners are quite pariative. From simple technology until modern technology is always attempted by teachers in meeting the criteria of student learning. First the learners maybe familiar with in the form of learning that are simple in theory then reality will be known by way of directly viewing the oject that want to learned. But with the development of technology that increasingly sophisticated, then developed technology applications that greatly help accelerate students understanding of the object being studied.

Besides that, teacher always expect the students' activeness in the process of learning takes place. For example asking or answering questions that asked by the teacher. But to attract students to answer the question sometimes the results are less than the maximum, even very rarely students who want to answer or ask to the teacher. That is caused because it is still a shame and anxiety, afraid to give answer or his question to teachers. So the learning situation becomes less active.

With the emergence of Guess the picture game that is often found in the Android world, it certainly becomes something that is quite interesting, not just among application game lovers, but this application is actually also interesting for the world of education as a supporting media in the learning process. Because in the learning process required supporting media that is able to create an a learning atmosphere that is not just struggling in the lecture method that is sometimes quite boring and very quickly forgotten, as well as the method of noting that aims to recall learning if after completion of the process of learning material presented sometimes also rarely read back. With the Guess the Picture Game, it is believed to be able to attract and stimulate the interest and creativity of learners to learn.

\section{RESULTS AND DISCUSSION}

2.1. Relevance of Guess the picture game as a learning media in the class.

Prior to state the Game guess the picture, first the writer wanted to elaborate about the need for and the importance of Technology's role in supporting the learning process or education contained in the 1945 Constitution, article 28 letter c, which states "Everyone has the right to develop themselves through fulfillment of their basic needs, are entitled to education and obtain benefit from science and technology, art, and culture in order to improve the quality of their lives and for the welfare of mankind. Thus national education expects technological progress as a means of supporting the progress of educational development in Indonesia. The Guess the picture is a game that can be accessed easily on Android phones. Where Game Guess the picture displays some questions that are very educational covering various fields of science. The questions presented seemed not only to attract the interest of children in primary and secondary education, but the quality of the questions presented included being suitable for the age of education. by bringing up a variety of images or displays, this image is then linked to the question raised [3]. The requirement to be able to answer this question is to recognize the picture and find out the name of the picture either in the form of Indonesian, Regional Language, English, or other specific languages. So this stimulates the mind to recognize the names of objects in the picture, and as well as is able to stimulate the mind to ask questions and stimulate the growth of thinking to discuss to complement each other's answers. This game is also very good to open up the insight of someone or learners 
to get to know something that they have never seen at all and they haven't known yet, and as well as vice versa, they can know more about something that has already been seen. Therefore, based on the observations and experience of the author, this Guess the Picture Game should be very suitable to be used as one of the supporting media in the classroom learning process, to increase students' interest to be more deeply involved about the knowledge that will be conveyed by the Teacher. Being involved more deeply that intended is how the students want to hear, speak, and be creative to do, assignments given. Usually to find students who brave to express the answers according to their abilities is very difficult, at least when educators ask two to five people, then the rest will be a good audience.

\subsection{Positive benefits of learning technology guess the picture Games}

In his writing Fahim Mohammad states that recently the Ministry of Education and Culture released a message via Facebook which contained an appeal to the public to recognize the rating system in video games [5]. In the message it is said that the new video game is worth played after the child reaches a certain age. Not only appealed for rating, the Ministry of Education and Culture also invited parents to accompany their children in choosing and playing video games.

In these weitings it is intended, Games that are presented easily in the android are not all negative, or it can be something which is positive. Therefore, here is also expected the role of parents or family in monitoring, accompany when the children want to play the game, which the goal is that the game that is played can function also or in other words the parents must choose a game that is suitable for their age, especially in increasing their scientific knowledge in the world of education in accordance with the character of Indonesian nation. As in this paper mentioned also some benefits of a game, which writers can correlate with the benefits of Game Guess the picture is among others:

a. Guess The Picture Game can be a means of entertainment or relaxation

It means that Game guess the picture contained in the android application is very helpful for children in the world of entertainment or relaxation but relaxation while getting the knowledge which there in it. This Guess Game is also able to relieve the stress of children after a day of learning in a school which sometimes feels a saturation in the learning process, so that with the existence of this game, it is a bit of a distraction and can restore children learning intentions, sometimes the question that is shown in the game there is a relation with the lesson that they get in the school.

b. As a bridge to instill interest in reading. Guess the picture game is also able to inculcate children's reading interest, for example seeking understanding of foreign languages or English that they do not know yet, as well as other sciences that is related with natural sciences and so on. Besides that, there are also many questions that are sometimes raised in English, it also pace children's learning interest to be more diligent in opening the English dictionary, as well as directly teaching them to speak English.

c. Train our reflexes and our ability to concentrate

In answering questions in this game, besides to understanding, mastering language, vocabulary, this game also requires the speed of the brain in thinking to find an answer, so that children can indirectly train their brain speed in finding an answer.

d. Give knowledge in arrange the strategy in the real world, as well as raising high spirits in learning to solve problems.

The image that displayed by this game must have a link between the images with each other in order to intertwined a sentence that forms a question. Therefore, the mindset of children directly trained 
with various strategies including case studies in solving problems.

e. Build confidence in solving every problem and build confidence in following the development of technological progress.

Building the confidence of children (students) is not an easy thing, in any learning implementation whether from the level of basic education to even college is very difficult to build the confidence of students especially in deliver questions, answers, or proposal and suggestions in each implementation learning. With this game is believed to be able to build children's confidence with the experience they get and build and inspire their confidence in mastering the development and advancement of technology, so they will not be too far behind in mastering technology.

Example Games Application Guess Image:

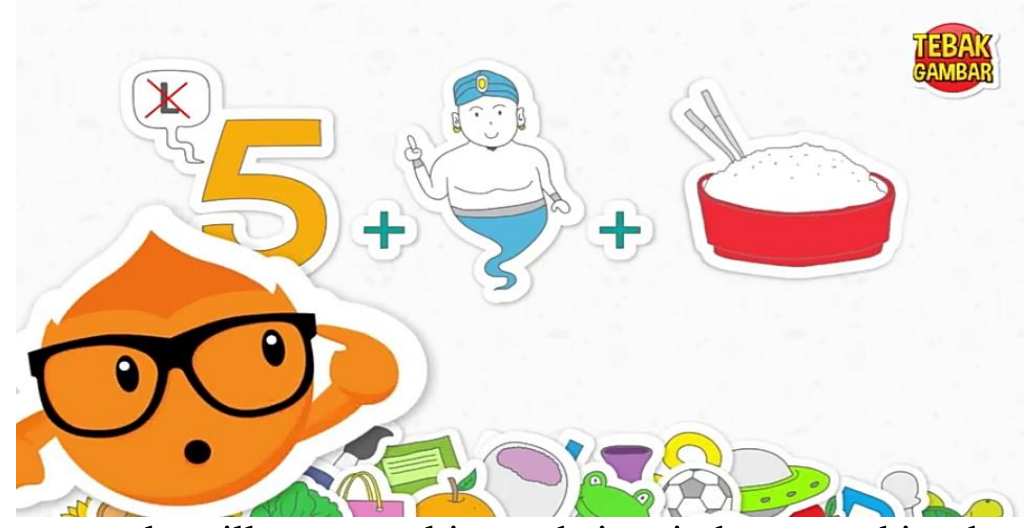

From this picture, people will try to cultivate their minds to combine between one of the picture to the next picture to be a conclusion of the answer.

This is the answer from this drawing game

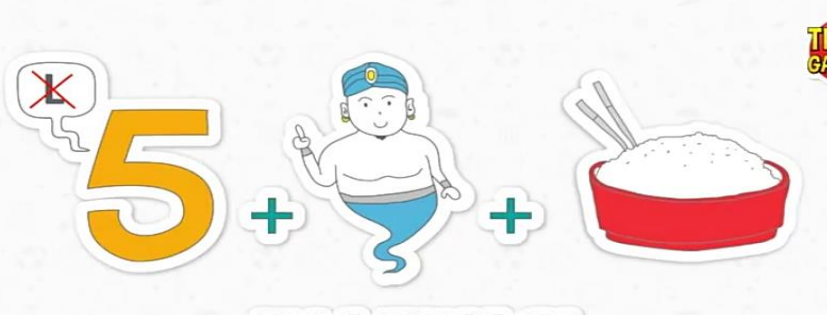

\section{IMAJINASI}

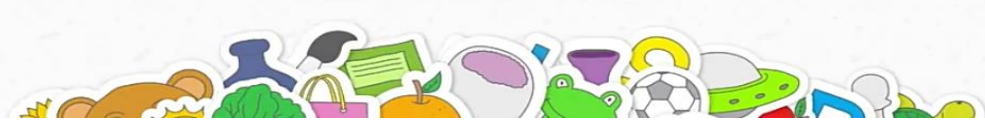

Another example for instance : 


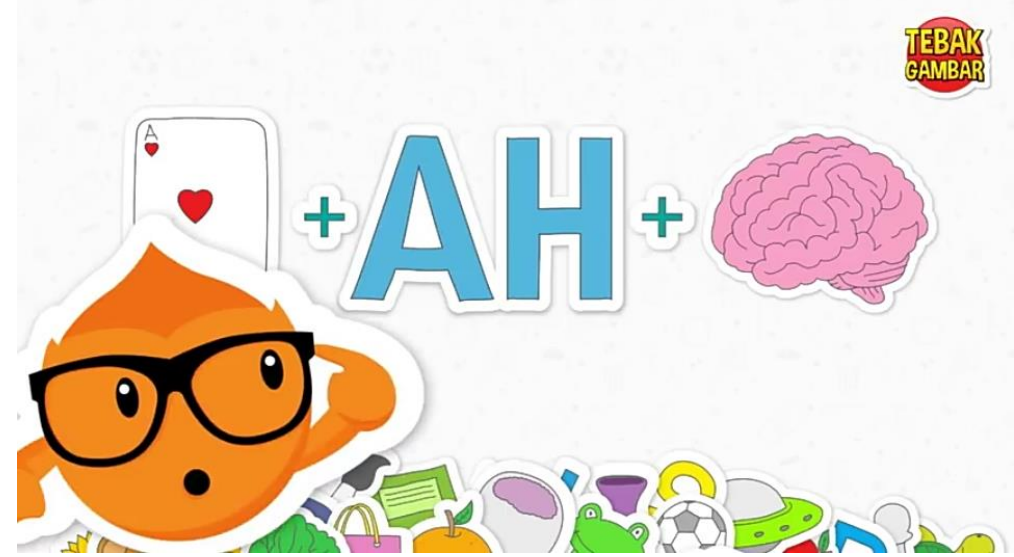

This picture has shown simply that someone is began to recognize and know the description of the human brain as a biology lesson.

The answers from this picture is as follows:

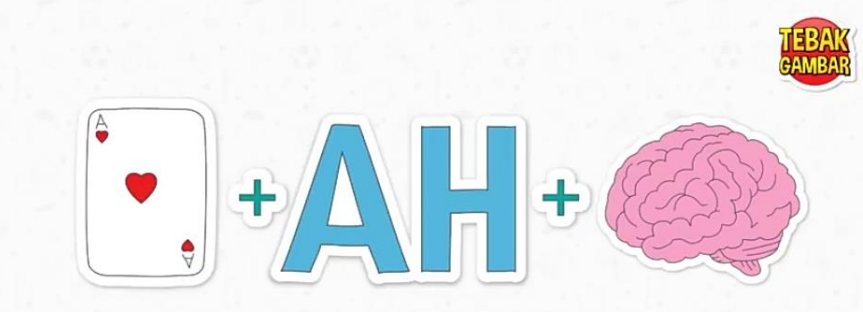

ASAH OTAK

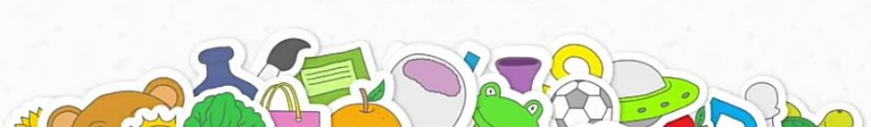

\section{CONCLUSION}

a. Guess the picture game is quite relevant to be developed to support the learning process in class by utilizing Game application technology and the role of educators to increase their knowledge and skills in following technological advances.

b. Benefits of guess the picture game is quite a lot besides as game media, this game is also able to increase student learning interest, confidence, and teach students not to be too left behind in the flow of technological advances.

\section{REFERENCES}

Ardianto, D. W., Fadlillah, U., \& Eng, S. T. M. (2016). Game 2D untuk Melatih Daya Ingat dan Konsentrasi Anak Menggunakan Construct 2 (Doctoral dissertation, Universitas Muhammadiyah Surakarta).
Asri, Y., \& Fitriani, Y. (2017, August). Flash flip book applications to measure the level of nationalism with quasi experiment on primary school students. In AIP Conference Proceedings (Vol. 1867, No. 1, p. 020062). AIP Publishing.

Chen, S. H., \& Tsai, M. Y. (2013). Using the Interactive Whiteboards to Teach Picture Books: The Case of Taiwan. International Education Studies, 6(11), 86-92.

Husnifa, R. (2017). The use of animation pictures to mprove students' vocabulary of seventh grade at mts tpi sawit Seberang (Doctoral dissertation, Universitas Islam Negeri Sumatera Utara).

Wells, P., \& Hardstaff, J. (2008). Reimagining animation: The changing face of the moving image. Bloomsbury Publishing. 